\title{
Kualitas Hidup Pasien Stroke dalam Perawatan Palliative Homecare
}

\author{
Ulfah N. Karim ${ }^{1}$, Erika Lubis ${ }^{1}$
}

\author{
${ }^{1}$ Medikal Bedah, Master of Nursing Program, STIKes Binawan, Jakarta, Indonesia \\ JI. Kalibata Raya No. 25-30, Cawang, Kramat Jati, RT.12/RW.5, Cawang, Kramatjati, \\ Kota Jakarta Timur, DKI Jakarta 13630 \\ Email: ulfah_karim@yahoo.com
}

\begin{abstract}
Abstrak
Stroke merupakan penyakit defisit neurologis multi kompleks yang menyebabkan kecacatan fisik atau mental dapat mempengaruhi semua aspek kehidupan individu termasuk kualitas hidup pasien. Kualitas hidup terkait kesejahteraan hidup pasien dan keluarga dengan pemberian perawatan Palliative homecare. Penelitian fenomenologi ini dilakukan untuk mengeksplorasi secara mendalam kualitas hidup pasien dalam perawatan Palliative homecare. Partisipan dalam penelitian ini dengan 13 partisipan dengan teknik purposive sampling. Tema yang terkait dengan kualitas hidup adalah domain fisik yang meliputi aktivitas, pola makan, memori dan konsentrasi, mobilitas fisik, bicara, nyeri, tidur dan istirahat. Domain psikologis antara lain gambaran diri, motivasi hidup, perasaan bahagia dan perasaan sedih. Domain sosial antara lain perubahan sosial antara lain perubahan fungsi sosial dan perubahan peran. Pengumpulan data dalam penelitian ini melalui data primer dan data sekunder. Data primer diperoleh dengan indepth interview (wawancara mendalam) kepada partisipan utama dan Fokus Group Discussion (FGD) kepada partisipan pendukung. Data sekunder menggunakan instrumen lain berupa formulir lembar data demografi, rekam medis berupa catatan medis, catatan keperawatan pasien dan catatan lapangan peneliti. Kualitas hidup domain fisik meningkat pada aktivitas, pola makan, mobilisasi fisik dan bicara. Kualitas hidup domain psikologis meningkat pada motivasi hidup, perasaan bahagia. Kualitas hidup domain sosial meningkat pada perubahan fungsi sosial. Penelitian ini berhasil membuktikan bahwa kualitas hidup pasien stroke meningkat dalam perawatan Palliative homecare. Perawatan Palliative homecare dalam informasi layanan dan kolaborasi dengan tim medis dan sosial worker sangat penting bagi peningkatan kebutuhan pasien dan pencapaian kualitas hidup.
\end{abstract}

Kata Kunci: stroke, quality of life, palliative homecare

\section{Quality of Life of Stroke Patients In The Care of Palliative Homecare}

\begin{abstract}
Stroke is a neurological deficit multi complex disease that causes physical or mental disability can affect all aspects of an individual's life, including the quality of life of patients. Quality of life related to the welfare of patients and families with the provision of Palliative homecare. Phenomenological study was conducted to explore in depth the quality of life of patients in palliative care homecare. Participants in this study with 13 participants using purposive sampling technique. Themes related to the quality of life is domains includes physical activity, diet, memory and concentration, physical mobility, speech, pain, sleep and rest. Psychological domains include self-image, motivation of life, happiness and sadness. Among other social domains of social change include changes in the social function and the role change. Collecting data in this study through primary data and secondary data. The primary data obtained by in-depth interviews (depth interview) to the main participants and Focus Group Discussion (FGD) to support participants. Secondary data using the other instruments in the form of sheet form and demographic data, medical records such as medical records, patient nursing records and field notes the researcher. Quality of life domains increased physical activity, diet, physical mobilization and talk. Quality of life increased in the psychological domain of motivation to live, feeling happy. Quality of life increased in the social domain changes in social function. This study proved that the quality of life of stroke patients in the care of palliative homecare increases. Palliative care in the
\end{abstract}


homecare information services and collaboration with the medical team and social worker is very important for improving the patient's needs and the achievement of quality of life.

Keywords: stroke, quality of life, palliative homecare

Info Artikel:

Artikel dikirim pada 16 Februari 2017

Artikel diterima pada 29 Maret 2017

DOI : http://dx.doi.org/10.21927/jnki.2017.5(1).42-50

\section{PENDAHULUAN}

Stroke atau CVD (Cerebro Vaskuler Disease) merupakan defisit neurologis secara mendadak susunan saraf pusat yang disebabkan oleh peristiwa iskemik atau hemoragik mempunyai etiologi dan patogenesis yang multi kompleks. Stroke menjadi penyebab utama kecacatan fisik atau mental pada usia lanjut maupun usia produktif dan dengan sifatsifatnya tersebut, menempatkan stroke sebagai masalah serius di dunia (1).

Berdasarkan data American Stroke Assosiation (ASA) tahun 2014 mendiskripsikan bahwa setiap tahun di Amerika Serikat (AS) $>690.000$ orang dewasa mengalami stroke meningkat sesuai dengan usia dan diperkirakan jumlah pasien stroke akan meningkat sebesar 30\% antara tahun 1983 dan $2023(2,3)$. Morbiditas terbesar stroke adalah adanya komplikasi akibat kerusakan neurologi, psikologi dan sosial yang mengakibatkan penurunan kesehatan serta resiko terjadinya kekambuhan (2).

Manifestasi klinis yang dapat muncul dari aspek fisik, psikologis dan sosial memerlukan penanganan secara cepat dan tepat pada fase rehabilitasi yang berdampak pada kualitas hidup. Pasien stroke yang memiliki keterbatasan fisik, kognitif dan sosial dapat menyebabkan menurunnya kualitas hidup (3).

Penilaian kualitas hidup pada pasien pasca stroke penting dalam praktek klinis, penelitian dan kebijakan kesehatan klinis serta evaluasi program (4). Oleh karena itu, salah satu tujuan dari rehabilitasi stroke adalah untuk meningkatkan kualitas hidup terkait kesehatan sehingga dapat mencapai tujuan dan kesejahteraan hidup pasien dan keluarga dengan perawatan Palliative homecare (5).

Pelayanan Palliative homecare di Indonesia sangat pesat, hal ini dikarenakan semakin kompleksnya dan bergesernya trend masalah kesehatan dari penyakit infeksi menjadi penyakit degenerative dan kronik, tingginya kebutuhan masyarakat akan akses pelayanan kesehatan yang terjangkau, terbatasnya sumber pelayanan kesehatan, pentingnya pelayanan kesehatan berkelanjutan serta sudah lama berkembang di negara maju dan didukung oleh pemerintah (6).

Peran perawat dalam perawatan Palliative homecare di fokuskan dalam pencegahan komplikasi dan mengurangi terjadinya stroke berulang, memberikan pendidikan kesehatan terkait perubahan gaya hidup dan pemberdayaan keluarga. Keluarga sebagai caregiver merupakan pendamping pasien dalam pemberian pelayanan perawatan kesehatan yang kompleks selama perawatan pasien pasca stroke (7).

Dukungan untuk keluarga pasien harus diberikan melalui sebuah usaha interdisiplin, yang melibatkan perawat, dokter, pasien dan keluarga serta pemerintah untuk dapat memberikan asuhan keperawatan yang holistik (8). Melihat berbagai fenomena terkait dengan kualitas hidup pasien yang diberikan layanan Palliative homecare, peneliti tertarik untuk mengeksplorasi lebih dalam bagaimana kualitas hidup pasien stroke dalam perawatan Palliative homecare.

Masalah utama yang dihadapi pasien stroke yaitu bagaimana keluarga, lingkungan dan tenaga medis mampu memberikan dan memenuhi kebutuhan perawatan pasien stroke dalam perawatan Palliative homecare, karena membutuhkan pendampingan untuk meningkatkan kemampuan dirinya walaupun dalam keterbatasan, sehingga kualitas hidupnya menjadi bermakna. Perawatan yang diberikan dapat dilakukan secara berkesinambungan, dengan perawatan Palliative homecare yang berkualitas. Maka kondisi pasien dengan stroke dapat memberikan efek membaik pada fisik maupun psikologisnya. Perawat sangat berperan dalam meningkatkan kualitas hidup pasien stroke. Tujuan penelitian ini adalah mengekplorasi kualitas hidup pasien stroke dalam perawatan Palliative homecare meliputi domain fisik, psikologis dan sosial. 


\section{BAHAN DAN METODE}

Penelitian ini menggunakan metode kualitatif eksploratif dengan pendekatan fenomenologi. Pendekatan fenomenologi yang digunakan dalam penelitian ini adalah deskriptif fenomenologi. Pendekatan fenomenologi didapatkan dari deskripsi kualitas hidup pasien stroke dengan menggali dan mendapatkan gambaran secara mendalam. Berbagai masalah pada pasien stroke baik masalah fisik, psikologi, sosial yang berdampak terhadap kualitas hidup sehingga menimbulkan masalah baik berasal dari keluarga, masyarakat maupun lingkungan.

Partisipan dalam penelitian ini ditentukan dengan teknik purposive sampling yakni teknik penentuan sampel dengan menseleksi kelompok partisipan menurut kriteria yang relevan dengan tujuan penelitian. Dalam hal ini untuk partisipan yang dijadikan kriteria adalah pasien yang mengalami stroke pada fase sub akut dan kronis yaitu: antara 2 minggu- 6 bulan pasca stroke dan Stroke fase kronis: diatas 6 bulan pasca stroke. Untuk mengukur kualitas hidup dapat diihat dari 2 kelompok partisipan yaitu partisipan utama adalah pasien dan atau pendamping pasien (caregiverl keluarga pasien), sedangkan partisipan pendukung adalah perawat dan atau dokter Palliative homecare. Jumlah partisipan ditentukan berdasarkan pada asas kesesuaian dan kecukupan informasi sampai mencapai saturasi data, yaitu peneliti tidak lagi memperoleh informasi baru dari partisipan. Partisipan dalam penelitian ini berjumlah 13 orang, yang terdiri dari 8 partisipan utama yaitu pasien stroke dan atau pendamping pasien (caregiver/keluarga pasien) yang mendapatkan perawatan di rumah lebih dari dua bulan (masa perawatan pasien stroke) dari unit paliatif care dan 5 partisipan pendukung yaitu perawat dan atau dokter dan psikolog.

Pengumpulan data dilaksanakan selama 2 bulan pada bulan April-Mei 2016. Penyusunan analisa data dan laporan penelitian pada bulan Juni-Juli 2016. Pengumpulan data dalam penelitian ini melalui data primer dan data sekunder. Data primer diperoleh dengan indepth interview (wawancara mendalam) kepada partisipan utama dan Fokus Group Discussion (FGD) kepada partisipan pendukung. Data sekunder melalui telaah dokumen di RS Kanker Dharmais di Jakarta Barat. Instrumen lain berupa formulir lembar data demografi, rekam medis berupa catatan medis, catatan keperawatan pasien dan catatan lapangan. Lembar pedoman wawancara berdasarkan beberapa penelitian terkait berdasar pada sumber EQ-5D-5L, namun peneliti mengembangkan sistem deskriptif terdiri dari berikut 5 dimensi: mobilitas, perawatan diri, kegiatan biasa, nyeri/ ketidaknyamanan dan kecemasan/depresi.

Dalam penelitian ini, digunakan uji keabsahan data berdasarkan kriteria credibility, baik dalam tahap prosedur sebelum pengumpulan data maupun selama pengumpulan data maupun selama analisa proses analisis data dengan teknik triangulasi teknik pengumpulan data dan sumber data, dan transferability, yaitu bertanggung jawab menyediakan deskripsi data yang cukup sehingga partisipan dapat mengevaluasi kesesuaian data.

Strategi dalam peningkatan reliabilitas penelitian kualitatif ada 2 cara yaitu: pertama audit proses penelitian (inquiry audit), yaitu caranya adalah audit terhadap konsistensi data dapat diperoleh dari hasil penelitian terhadap data primer yang autentik, proses reduksi data melalui koding tematik dan analitik serta bukti hasil koding yang tersimpan dalam nodes. Pengukuran secara akurat menggunakan software $N$ Vivo 11 Pro, kedua penjelasan detail tentang proses pengumpulan data, yaitu proses penelitian harus dijelaskan dengan detail untuk membantu peneliti selanjutnya dalam mengulangi replikasi penelitian yang sama dalam konteks yang berbeda.

Analisis data awal (prelimenary analysis) melalui teknik koding dengan menggunakan Software NVivo 11 Plus. Teknik analisis tematic (thematic analysis) dan analisis perbandingan (comparative cross analysis) data disesuaikan dengan tahapan analisis data kualitatif yang dikemukakan oleh Colaizzi.

\section{HASIL DAN BAHASAN}

\section{Hasil Analisis Data Tematik}

Selama proses penelitian berlangsung, ditemukan 3 tema utama yang terdiri dari domain fisik, domain psikologis dan domain sosial, disajikan dalam Gambar 1

\section{Kualitas Hidup Domain Fisik}

Sub tema pada kualitas hidup domain fisik antara lain aktivitas, pola makan, memori dan konsentrasi, mobilitas fisik, bicara, nyeri, tidur dan istirahat, disajikan dalam Gambar 2.

\section{Kualitas Hidup pada Domain Psikologis}

Sub tema pada domain psikologis antara lain gambaran diri, motivasi hidup, perasaan bahagia dan perasaan sedih, disajikan dalam Gambar 3. 


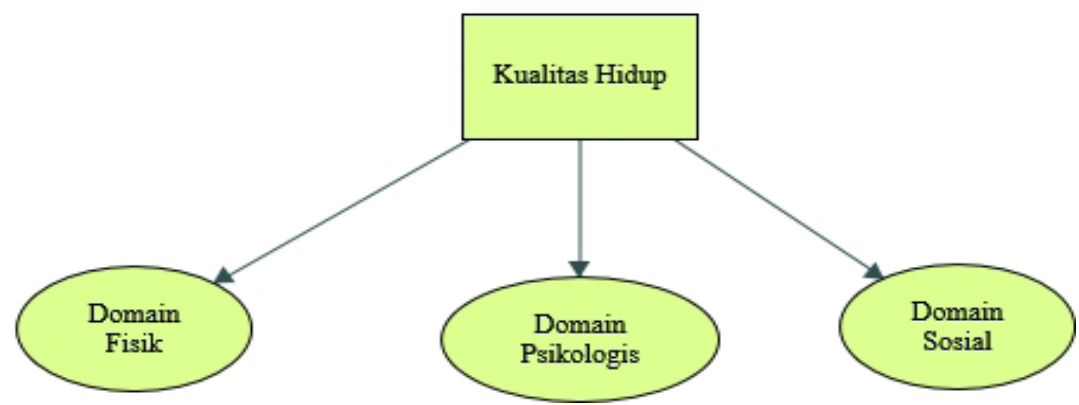

Gambar 1. Skema Model Tema utama dalam penelitian

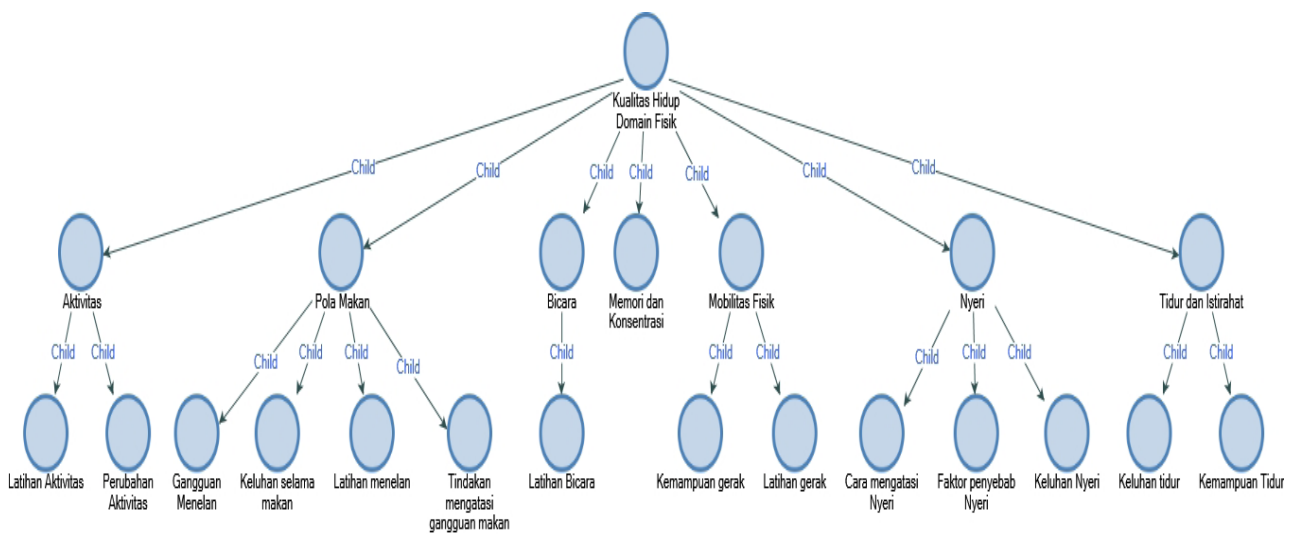

Gambar 2. Sub Tema dan Sub Sub Tema pada Kualitas Hidup Domain Fisik Pasien Stroke dalam Perawatan Palliative Homecare

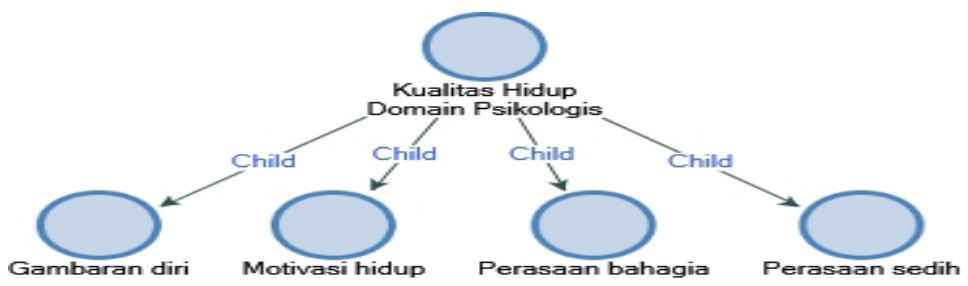

Gambar 3. Sub Tema pada Domain Psikologis Pasien Stroke dalam Perawatan Palliative Homecare

\section{Kualitas hidup pada domain sosial}

Sub tema pada domain sosial antara lain perubahan sosial antara lain perubahan fungsi sosial dan perubahan peran, disajikan dalam Gambar 4.

\section{Hasil Analisis Data Komparatif}

\section{Domain Fisik}

Informan yang paling banyak menyampaikan perubahan fisik yang dialami adalah aktivitas, pola makan, mobilisasi fisik serta bicara, disajikan dalam

\section{Gambar 5.}

Berikut adalah beberapa transkrip wawancara dengan beberapa partisipan. Informan 5 menyatakan bahwa "..... pasien sudah bisa makan sendiri hanya dibantu aktivitas yang lain", informan 6 menyatakan bahwa "...perubahan aktivitas, seperti ibu...., dulu sudah bagus, pasien sudah bisa jalan dan bisa makan", informan 7 menyatakan bahwa "....aktivitas dari dibantu perawat sekarang pake caregiver....", informan 8 menyatakan bahwa "....aktivitas mesti dilatih dengan tim dari kami terutama fisioterapi", informan 9 menyatakan bahwa "...jadi dibantu secara penuh dan pasien bisa terlihat menjadi lebih baik".

Informan 6 menyatakan bahwa ".....perubahan fisik lebih cepat perkembangannya makan bisa kelihatan langsung dapat mengurangi beban keluarga". Informan menyatakan bahwa "....bisa makan sendiri, pola makan ada peningkatan, pasien sudah bisa makan sendir".

Berdasarkan hasil FGD 1 (informan 5-9) menyatakan bahwa secara fisik, duduk di kursi, kalau perubahan fisik lebih cepat perkembangannya, fisioterapi: secara fisik sudah baik, sudah nyaman: tidak ada masalah fisik. 


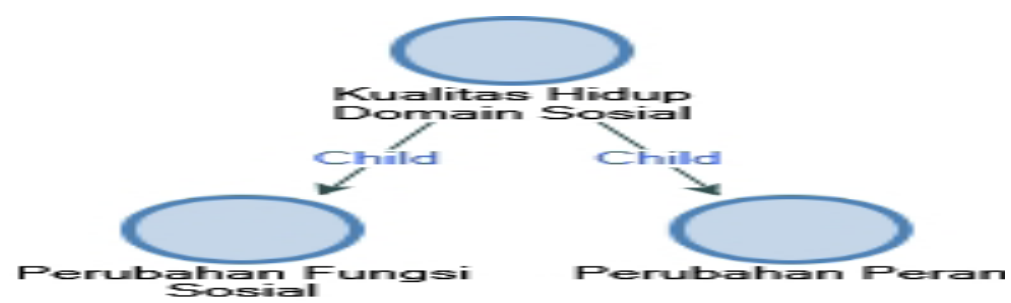

Gambar 4. Tema dan Sub Tema pada Domain Sosial Pasien Stroke dalam Perawatan Palliative Homecare

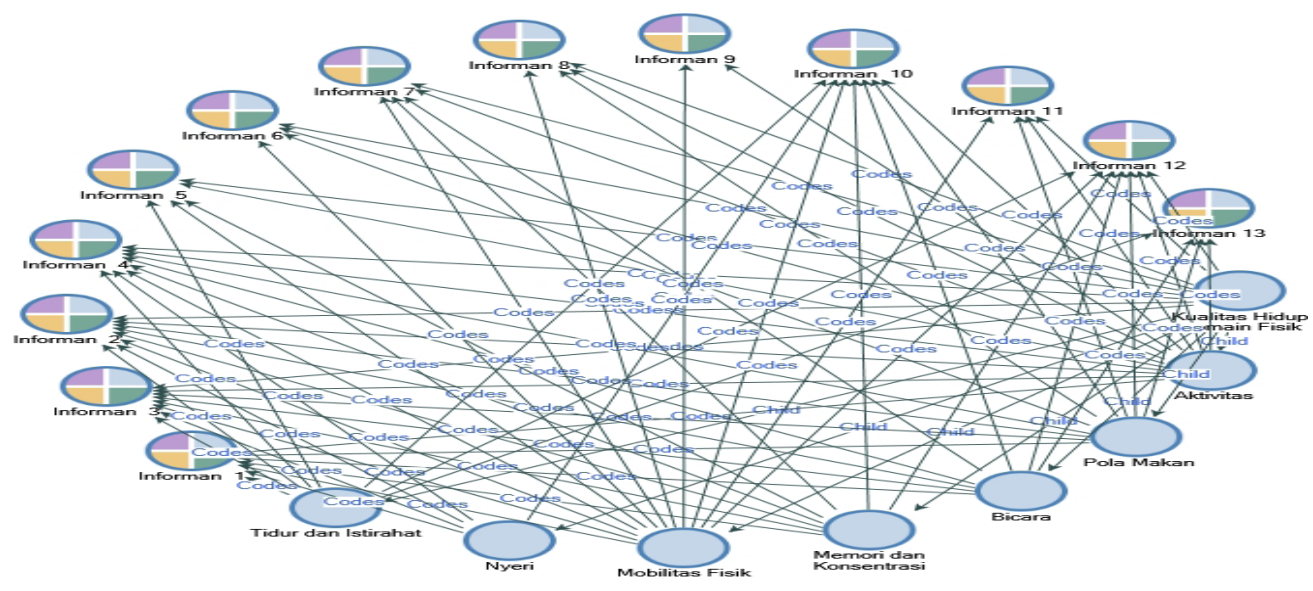

Gambar 5. Analisa Komparatif Kualitas Hidup Domain Fisik

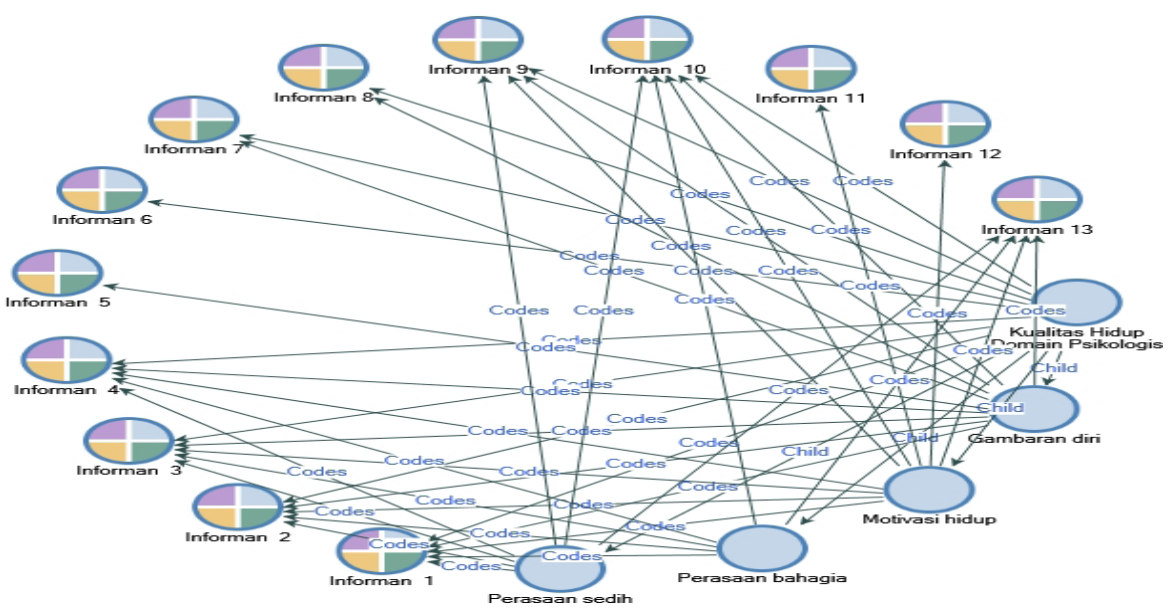

Gambar 6. Analisa Komparatif Kualitas Hidup Domain Psikologis

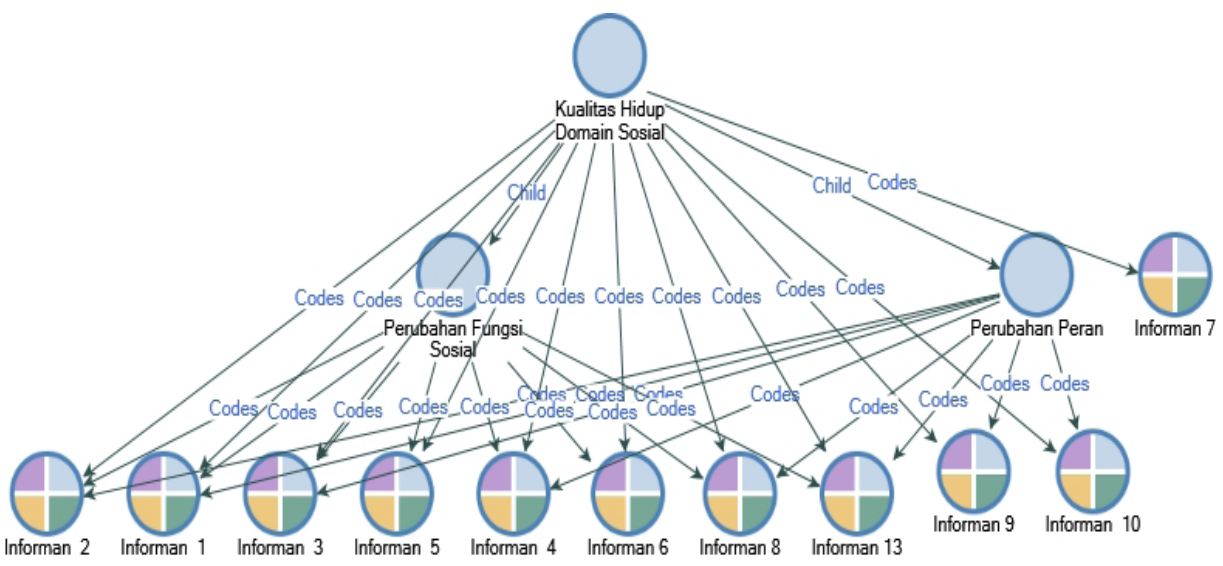

Gambar 7. Analisa Komparatif Kualitas Hidup Domain Sosial 
Berdasarkan hasil FGD 1 (informan 7) menyatakan bahwa untuk mengungkapkan, secara fisik: bisa bicara, perkembangannya cara bicara dan sudah bisa bicara, perkembangan cepat dan baik. Informan 7 menyatakan bahwa "ibu... sulit untuk mengungkapkan, secara fisik: bisa bicara, ibu .... sudah bisa jalan dan sudah bisa bicara, perkembangan cepat dan baik kalau di rumah".

\section{Domain Psikologis}

Informan yang paling banyak menyampaikan perubahan psikologis yang dialami adalah gambaran diri, motivasi hidup, perasaan bahagia dan perasaan sedih, yang disajikan dalam Gambar 6 .

Penyakit stroke akan berdampak pada kondisi psikologis informan, kondisi psikologis merupakan kemampuan psikologis untuk berfungsi secara optimal sehingga dapat melakukan kepuasan hidup dan pencapaian tujuan hidup untuk memenuhi kebutuhan hidupnya. Pasien stroke yang dilakukan perawatan Palliative homecare dengan keadaan psikologis mengalami gangguan maka dampaknya akan semakin kompleks mempengaruhi kondisi yang lainnya. Informan yang paling banyak menyampaikan banyak perubahan psikologis yang dialami adalah gambaran diri, motivasi hidup, perasaan bahagia dan perasaan sedih.

Berikut adalah beberapa transkrip hasil wawancara dengan beberapa partisipan. Informan 5 menyatakan bahwa "lbu... sekarang membangun kepercayaan diri untuk turun dari tempat tidur". Informan 6 menyatakan bahwa "...pasien sangat menjadi depresi dan menurun kepercayaan diri karena masalah psikologis, sehingga keluarga mampu menjadi suporting yang baik". Informan 7 menyatakan bahwa "pasien menjadi sedih".

Berdasarkan hasil FGD 3 (informan 12 dan 13) menyatakan bahwa selama di rumah semangat, ada kemajuan, semangat ke saya, selalu kasih semangat dan diajak ngobrol. Informan 12 menyatakan bahwa "....selama di rumah: oma semangat, ada kemajuan, semangat".

Berdasarkan hasil FGD 7 (informan 8) yang menyatakan bahwa "... lebih senang sudah banyak perubahan, seperti ibu.... keluarga sama kita sudah dekat, sudah seperti keluarga, senang kalau kita datang".

Berdasarkan hasil FGD 1 (informan 9) menyatakan bahwa ".... seperti ibu.... sedih lihat anaknya, tidak semangat dan kurang percaya diri atau takut, kalau kita ada yang datang.... menangis, takut jatuh, jadi mesti ada yang mengawasi".

\section{Domain Sosial}

Informan yang paling banyak menyampaikan perubahan sosial yang dialami adalah perubahan fungsi sosial dan perubahan peran, disajikan dalam Gambar 7.

Penyakit stroke akan berdampak pada kondisi sosial informan, kondisi sosial merupakan menggambarkan adanya bantuan yang didapatkan oleh individu yang berasal dari lingkungan sekitarnya, mencakup relasi personal, dukungan sosial dan aktivitas sosial. Pasien stroke yang dilakukan perawatan Palliative homecare dengan keadaan sosial mengalami gangguan maka dampaknya akan semakin kompleks mempengaruhi kondisi yang lainnya. Informan yang paling banyak menyampaikan banyak perubahan sosial yang dialami adalah perubahan fungsi sosial dan perubahan peran.

Berikut adalah beberapa transkrip hasil wawancara dengan beberapa partisipan. Berdasarkan hasil FGD 1 (informan 9) yang menyatakan bahwa adanya ".....perubahan segi sosial. Stroke perlu sosial worker, perlu intens fisioterapi, kurang memberikan dukungan sehingga kondisi sosial pasien menurun, adanya perubahan peran, kurangnya dukungan sosial dan keterbatasan sosial".

Berdasarkan hasil FGD 1 (informan 9) menyatakan bahwa "yang penting pasien di fase mana, fase penyembuhan pasien, prognosis, peran keluarga, caregiver, peranan dari tim peran keluarga sangat penting, adanya perubahan peran, kurangnya dukungan sosial dan keterbatasan".

Kualitas hidup informan berdasarkan domain fisik mengalami peningkatan pada perubahan aktivitas, dimana kondisi ini dilihat dari perubahan selama pasca perawatan di rumah sakit dan di lakukan perawatan homecare. Hal ini didukung oleh teori bahwa gangguan neuromuscular dapat memengaruhi aktivitas perawatan diri pasien yang mengalami stroke akan mengalami gangguan dalam aktivitas hidup sehari-hari (9).

Dalam penelitian terkaityang telah dilakukan pada pasien dengan stroke yang memerlukan perawatan Palliative homecare dengan judul "Associations Between Quality of Life and Sosioeconomic Factors, Functional Impairments and Dissatisfaction with Received Information and Home care Services Among Survivors Living at Home Two Years After 
Stroke Onset", penelitian oleh Baumann, bertujuan untuk mengeksplorasi pengalaman pasien setelah 2 tahun pasca stroke yang mendapat pelayanan perawatan Palliative homecare. Penelitian ini menunjukkan bahwa dua tahun setelah onset stroke, pasien merasakan kualitas hidup adalah nyata rendah untuk domain berikut: emosi, tidur, kognitif, komunikasi, mobilitas, perasaan mental, rasa sakit dan kelelahan (yang umumnya dikenal sebagai gejala depresi) (8).

Kualitas hidup informan berdasarkan domain fisik mengalami peningkatan pada perubahan pola makan, dimana kondisi ini dilihat dari perubahan selama pasca perawatan di rumah sakit dan di lakukan perawatan Palliative homecare, pasien mengalami perubahan pola makan dari fase akut, dimana makan dibantu dengan alat karena pasien mengalami gangguan menelan, maka untuk perawatan di rumah pasien sudah mampu menelan. Penelitian ini didukung oleh teori bahwa disfungsi motor yang paling umum adalah hemiplegia (kelumpuhan satu sisi tubuh, atau bagian dari itu) yang disebabkan oleh lesi dari sisi yang berlawanan dari otak, hemiparese atau kelemahan dari salah satu sisi tubuh, atau bagian dari itu atau tanda lain kelemahan pada wajah dan termasuk gangguan menelan. Pada awal tahap stroke, awal gambaran klinis mungkin placid paralisis dan kehilangan atau penurunan dalam sepuluh reflex tendon (10).

Pada aplikasi menurut teori Roy, penemuan ini dapat dilihat bahwa pasien mengalami proses kontrol kedalam sub sistem stabilizer dimana mengalami gangguan menelan dan perubahan pola makan akibat placid paralisis yang dialami, tidak mampu untuk makan sehingga dibantu dengan alat bantu makan yaitu NGT. Pemenuhan pola makan dibantu oleh caregiver dan keluarga. Sub sistem regulator dari pasien mengalami untuk kestabilan menjaga kemampuan beraktivitas fisik yang ditandai dengan latihan menelan dan proses belajar dengan kondisi yang ada. Sub sistem innovator berhubungan dengan sub sistem cognator yang berfokus pada kemampuan pasien dalam beradaptasi dengan kondisi yang sekarang dan mengalami perubahan dan peningkatan yaitu pasien mampu menelan dan mau makan.

Kualitas hidup informan berdasarkan domain fisik mengalami peningkatan pada perubahan mobilisasi fisik dibandingkan saat terjadi stroke pada fase akut, dimana kondisi ini terjadi peningkatan kemampuan pasien dalam melakukan mobilisasi fisik selama rehabilitasi. Pada aplikasi menurut teori Roy, dapat dilihat bahwa pasien dengan model adaptasi fisiologi berfokus pada cara manusia berinteraksi dengan lingkungan melalui proses fisiologi khususnya pasien telah mengalami perubahan fisik yaitu kemampuan mobilisasi fisik dengan mampu duduk dan berlatih jalan sesuai tahap penyembuhan dan kemampuan fisik pasien $(11,12)$.

Kualitas hidup informan berdasarkan domain fisik mengalami peningkatan pada perubahan bicara dibandingkan saat terjadi stroke pada fase akut, dimana kondisi ini terjadi peningkatan kemampuan pasien dalam melakukan bicara selama rehabilitasi. Penelitian ini didukung oleh teori bahwa setelah stroke pasien mengalami masalah kognitif, perilaku dan penurunan emosi akibat kerusakan otak. Kadang derajat fungsi yang penting dapat kembali pulih karena tidak semua daerah otak rusak bersamasama, beberapa yang tersisa lebih utuh dan berfungsi daripada yang lain (9).

Kualitas hidup informan berdasarkan domain psikologis mengalami penurunan khususnya pada tema gambaran diri. Hal ini terjadi karena pasien dalam kondisi menurun secara aspek fisik khususnya pada gangguan fungsional neurologis seperti gangguan memori dan konsentrasi, nyeri dan kemampuan tidur dan istirahat pasien, sehingga akan menjadi pengaruh pada domain psikologis. Perubahan ini dapat menyebabkan pasien menjadi mudah frustasi selama rehabilitasi. Depresi adalah umum dan dapat dibesar-besarkan oleh respon alami pasien untuk peristiwa ini. Emosi labil, frustasi, dendam, kurangnya kerjasama, dan masalah psikologis lainnya dapat terjadi (10).

Kualitas hidup informan berdasarkan domain psikologis mengalami peningkatan khususnya pada tema motivasi hidup. Hal ini terjadi karena pasien dalam kondisi meningkat secara aspek fisik khususnya pada gangguan fungsional neurologis seperti gangguan aktivitas, pola makan, mobilisasi fisik dan bicara, sehingga akan menjadi pengaruh pada domain psikologis.

Kualitas hidup informan berdasarkan domain psikologis mengalami peningkatan khususnya pada tema perasaan bahagia. Penelitian ini didukung oleh teori bahwa gangguan psikologis non spesifik yang dialami pasien stroke seperti, depresi, kecemasan (9). Kualitas hidup informan domain psikologis mengalami penurunan pada perasaan sedih, dimana ada beberapa faktor yang mempengaruhi diantaranya 
menurunnya gangguan memori dan konsentrasi, nyeri dan kemampuan tidur dan istirahat pasien, sehingga akan menjadi pengaruh pada domain psikologis.

Kualitas hidup berdasarkan domain sosial pasien mengalami peningkatan pada perubahan fungsi sosial selama di rumah. Perubahan sosial yang dialami oleh pasien, dimana pasien memiliki keluarga atau caregiver yang mendampingi selama perawatan di rumah, didukung oleh tim medis dan sosial worker yang melakukan kunjungan dan pelayanan medis secara kontinu, sehingga terjadi peningkatan fungsi sosial.

Kualitas hidup yang rendah dilihat dari perubahan peran yaitu perbedaan peran dan tugas pasien dalam keluarga. Pada gangguan fungsional dilihat kualitas hidup rendah dimana saling bergantung dengan aspek yang lain terutama pasien yang mewakili gejala depresi (perasaaan sedih).

Gardiner mengamati bahwa partisipasi dalam rehabilitasi stroke pasien dibentuk oleh sikap yang menguntungkan, motivasi, jaminan finansial dan penyediaan informasi (7). Kepatuhan terhadap pengobatan lebih baik antara pasien yang merasakan pelayanan dan komunikasi terapeutik menjadi tinggi. Namun, informasi dan pelayanan perawatan Palliative homecare tidak dapat diberikan secara adil, meninggalkan orang-orang dengan kesulitan sosial ekonomi dengan kurangnya penjelasan, pengobatan dan kepatuhan pengobatan.

\section{SIMPULAN DAN SARAN}

Penelitian ini menggambarkan kualitas hidup pasien stroke dalam perawatan Palliative homecare dengan melihat 3 domain yaitu domain fisik, domain psikologis dan domain sosial. Penelitian ini menggambarkan kualitas hidup pasien stroke dalam perawatan Palliative homecare yang menunjukkan bahwa pasien memiliki gangguan fungsional terkait dengan peningkatan kualitas hidup di sejumlah domain fisik, adalah aktivitas, pola makan, mobilisasi fisik dan bicara.

Kualitas hidup informan domain psikologis mengalami peningkatan motivasi hidup dan perasaan bahagia. Kemampuan aktivitas fisik, pola makan, mobilisasi fisik dan bicara meningkat, sehingga mempengaruhi motivasi hidup dan perasaan bahagia. Kualitas hidup informan domain psikologis mengalami penurunan pada gambaran diri dan perasaan sedih, dimana ada beberapa faktor yang mempengaruhi diantaranya gangguan fisik, khususnya menurunnya gangguan memori dan konsentrasi, nyeri, tidur dan istirahat, serta kurangnya dukungan sosial.

Berbagai domain kualitas hidup pada perubahan fungsi sosial mengalami peningkatan khususnya terkait dengan peningkatan dukungan keluarga dan lingkungan, perubahan fisik dengan gejala sisa yang dialami. Kualitas hidup yang rendah dilihat dari perubahan peran yaitu ketidakmampuan pasien dalam pemenuhan peran dan tugas dalam keluarga yang berpengaruh terhadap lingkungan dan adaptasi terhadap kondisi kesehatan selama perawatan Palliative homecare.

\section{RUJUKAN}

1. Hinkle JL, Cheever KH. No TitleBrunner \& Suddarths Textbook of Medical Surgical Nursing 13 th Edition. Philadelphia: Lippincott Williams \& Wilkins; 2014.

2. Kernan WN, Ovbiagele B, Black HR, Bravata DM, Chimowitz MI, Ezekowitz MD, et al. Guidelines for the prevention of stroke in patients with stroke and transient ischemic attack: a guideline for healthcare professionals from the American Heart Association/American Stroke Association. Stroke [Internet]. 2014 Jul;45(7):2160-236. Available from: http://www.ncbi.nlm.nih.gov/ pubmed/24788967.

3. Prlić N, Kadojić D, Kadojić M. Quality of life in poststroke patients: self-evaluation of physical and mental health during six months. Acta Clin Croat [Internet]. 2012 Dec;51(4):601-8. Available from: http://www.ncbi.nlm.nih.gov/pubmed/23540168.

4. Kim K-J, Heo M, Chun I-A, Jun H-J, Lee J-S, Jegal $H$, et al. The relationship between stroke and quality of life in Korean adults: based on the 2010 Korean community health survey. J Phys Ther Sci [Internet]. 2015;27(1):309-12. Available from: https://www.jstage.jst.go.jp/article/ jpts/27/1/27_jpts-2014-435/_article.

5. Badaru U, Ogwumike O, Adeniyi A. Quality of life of Nigerian Stroke Survivors and Its Determinants. African J Biomed Res. 2015;18(1):1-5.

6. Campbell M. Nurse to Nurse Perawatan Paliatif. Jakarta: Salemba Medika; 2012.

7. Gardiner C, Harrison M, Ryan T, Jones A. Provision of palliative and end-of-life care in stroke units: a qualitative study. Palliat Med [Internet]. 2013 Oct;27(9):855-60. Available from: http:// www.ncbi.nlm.nih.gov/pubmed/23579262. 
8. Baumann M, Le Bihan E, Chau K, Chau $\mathrm{N}$. Associations between quality of life and socioeconomic factors, functional impairments and dissatisfaction with received information and home-care services among survivors living at home two years after stroke onset. BMC Neurol [Internet]. 2014 Apr 28;14:92. Available from: http://www.ncbi.nlm.nih.gov/pubmed/24773696.

9. Smeltzer SC. Brunner \& Suddarth Textbook of Medical Surgical Nursing. Philadelphia: Wolters
Kluwer Health/Lippincott Williams \& Wilkins; 2010.

10. Black JM, Hawks JH. Medical Surgical Nursing. Clinical Management for Positive Outcomes. Singapore: Elsevier; 2009.

11. Alligood MR. Nursing Theorist and Their Work. Mosby: Elsevier; 2014.

12. Mc Ewen M. Theorectical Basis for Nursing. 3rd ed. Philadelphia: Woters Kluwer. Lippincott William \& Wilkins; 2011. 